\section{GW23-e1013 RELATIONSHIP BETWEEN ATRIAL FIBRILLATION CARDIOVERSION AND F}

doi:10.1136/heartjnl-2012-302920t.3

Liufan Lixuan. The Second Hospital of Hebei Medical University

Objectives To investigate the relationship between atrial fibrillation cardioversion and $\mathrm{f}$ wave in electrocardiogram, providing an ordinary and noninvasive method for the clinical prediction and treatment

Methods We selected 50 cases of patients with atrial fibrillation living in our hospital and divided into two groups according to the size of each indictors, such as $\mathrm{f}$ wave discrepancy, $\mathrm{f}$ wave amplitude, $\mathrm{f}$ wave duration, diameter of the left atrial, left ventricular ejection fraction and plasma BNP level. (f wave duration $\geq 110 \mathrm{~ms}$ vs $\mathrm{f}$ wave duration $<110 \mathrm{~ms}$; $\mathrm{f}$ wave discrepancy $<50 \mathrm{~ms}$ vs $\mathrm{f}$ wave discrepancy $\geq 50 \mathrm{~ms}$; f wave amplitude $\geq 0.1 \mathrm{mv}$ vs $\mathrm{f}$ wave amplitude $<0.1 \mathrm{mv}$; diameter of the left atrial $<40 \mathrm{~mm}$ vs diameter of the left atrial $\geq 40 \mathrm{~mm}$; left ventricular ejection fraction $\geq 50 \%$ vs left ventricular ejection fraction $<50 \%$; plasma BNP level $<200 \mathrm{mmol} / \mathrm{l}$ vs plasma BNP level $\geq 200 \mathrm{mmol} / \mathrm{l}$ ). We observed the rate of atrial fibrillation within $72 \mathrm{~h}$ and calculated the predictive value of indicators for atrial fibrillation cardioversion.

\section{Results}

1. The diversion rate from atrial fibrillation was $69 \%$ in group of $f$ wave duration $\geq 110 \mathrm{~ms}$ vs $35 \%$ in group of $f$ wave duration $<110 \mathrm{~ms}(\mathrm{p}<0.05), 55 \%$ in group of $\mathrm{f}$ wave discrepancy $<50 \mathrm{~ms}$ vs $24 \%$ in group of $\mathrm{f}$ wave discrepancy $\geq 50 \mathrm{~ms}(\mathrm{p}<0.05), 60 \%$ in group of $\mathrm{f}$ wave amplitude $\geq 0.1 \mathrm{mv}$ vs $28 \%$ in group of $\mathrm{f}$ wave amplitude $<0.1 \mathrm{mv}(\mathrm{p}<0.05), 70 \%$ in group of the left atrial diameter $<40 \mathrm{~mm}$ vs $22 \%$ in group of the left atrial diameter $\geq 40 \mathrm{~mm}$ ( $\mathrm{p}<0.05), 54 \%$ in group of left ventricular ejection fraction $\geq 50 \%$ vs $15 \%$ in group of left ventricular ejection fraction $<50 \%, 62 \%$ in group of plasma BNP level $<200 \mathrm{mmol} / \mathrm{l}$ vs $25 \%$ in group of plasma BNP level $\geq 200 \mathrm{mmol} / \mathrm{l}(\mathrm{p}<0.05)$.

2. Receiver operating characteristic curve show that: area under the curve of $f$ wave duration $\geq 110 \mathrm{~ms}$ was 0.71 , of $f$ wave discrepancy $<50 \mathrm{~ms}$ was 0.70 , of $\mathrm{f}$ wave amplitude $\geq 0.1 \mathrm{mv}$ was 0.70 , of the left atrial diameter $<40 \mathrm{~cm}$ was 0.76 , of left ventricular ejection fraction $\geq 50 \%$ was 0.70 , of plasma BNP level $<200 \mathrm{mmol} / \mathrm{l}$ was 0.73 , all larger than 0.7 , with $\mathrm{p}$ value all less than 0.05 . So all of them had diagnostic value to some extent. When the Youden's index index(YI)reach maxism, their cut point were $78 \mathrm{~ms}, 42 \mathrm{~ms}, 1.0 \mathrm{mv}, 39.5 \mathrm{~mm}, 60 \%, 207 \mathrm{mmol} / 1$.

3. Among single risk factor, the specificity, sensitivity, positive predictive value and negative predictive value of $\mathrm{f}$ wave duration $\geq 110 \mathrm{~ms}$ were $41 \%, 86 \%, 69 \%, 65 \%$; the specificity, sensitivity, positive predictive value and negative predictive value of $\mathrm{f}$ wave dispersion $<50 \mathrm{~ms}$ were $82 \%, 46 \%, 55 \%$, 76\%; the specificity, sensitivity, positive predictive value and negative predictive value of $\mathrm{f}$ wave amplitude $\geq 0.1 \mathrm{mv}$ were $68 \%, 64 \%, 60 \%, 72 \%$; the specificity, sensitivity, positive predictive value and negative predictive value of the left atrial diameter $<40 \mathrm{~mm}$ were $73 \%, 75 \%, 70 \%, 78 \%$; the specificity, sensitivity, positive predictive value and negative predictive value of left ventricular ejection fraction $\geq 50 \%$ were $91 \%, 39 \%, 54 \%$, $85 \%$; the specificity, sensitivity, positive predictive value and negative predictive value of plasma BNP level $<200 \mathrm{mmol} / \mathrm{l}$ were $73 \%$, $64 \%$, $62 \%, 75 \%$, the sensitivity and negative predictive value of left ventricular ejection fraction $\geq 50 \%$ to predict cardioversion of atrial fibrillation was highest, and the specificity and positive value of $f$ wave duration $\geq 110 \mathrm{~ms}$ to predict cardioversion of atrial fibrillation was highest. Along with more than two risk factors, the specificity and negative predictive value were much higher, but the sensitivity and positive predictive value were much lower. Multiple logistic regression analysis revealed that the $f$ wave amplitude was an independent predictor of cardioversion of atrial fibrillation.

Conclusions $\mathrm{F}$ wave characteristics are electrocardiographic markers that can be used for the prediction of cardioversion of atrial fibrillation. 